\title{
Vinícius de Moraes: o poetinha-letrista da literatura infantil brasileira
}

\author{
Janete de Jesus Serra COSTA ${ }^{1}$ \\ Vanessa Soeiro CARNEIRO
}

“A infầncia é o arquétipo da felicidade simples”. (Gaston Bachelard, 2009, p.118).

Resumo: O presente estudo apresenta algumas considerações acerca da poesia infantil modernista no Brasil, ressaltando o contexto estético desse período e as características da linguagem literária. Para tanto, destaca-se a contribuição para este gênero de um dos maiores poetas e compositores da música popular brasileira, Vinícius de Moraes, bem como de sua única obra infantil, A arca de Noé, publicada na década de 70. Este trabalho tem como objetivo analisar a poeticidade dos textos literários presentes nessa antologia. Para isso, quatro poemas que compõem esse livro foram escolhidos para serem analisados: A arca de Noé, O girassol, O pato e Os bichinhos e o homem. A escolha por analisar esses poemas aconteceu devido a sua temática e a sua estrutura. O trabalho está fundamentado em pesquisa bibliográfica, embasado em um profícuo diálogo entre os postulados da teoria e da crítica literária, como de Arroyo (2011), Coelho (2006), Lajolo (2002), Zilberman (2009), dentre outros.

Palavras-chave: Poesia. Crianças. Vinícius de Moraes.

Abstract: This paper presents some considerations about the modernist childish poetry in Brazil, bouncing the esthetic context of the period and the literary language characteristics. Therefore, we detach theimportant contribution to this genre of one of the greatest poets and composers of Brazilian popular music, Vinicius de Moraes, and his only childishwirk, $A$ arca de Noé, published in the 70s. This paper aims to analyze the poetic literary texts present in this anthology. Therefore, we chose four poems that compose this book be analyzed $A$ arca de Noé, $O$ girassol, $O$ pato and Os bichinhos e o homem. The choice to analyze these poems happened due its themes and its structure. This work is based on a literature review, based on a fruitful dialogue between the postulates of the theory and literary criticism, as Arroyo (2011), Coelho (2006), Lajolo (2002), Zilberman (2009), among others.

Keywords: Poetry. Children. Vinícius de Moraes.

\section{Introdução}

A etimologia da palavra "lírica" é derivada do gregolyra e do latim lira, nome do instrumento musical de corda utilizado pelos gregos durante os momentos de recitação e de

\footnotetext{
${ }^{1}$ Professora substituta do Departamento de Letras da Universidade Federal do Maranhão. Mestre em Cultura e Sociedade/UFMA. Integrante do Grupo de Pesquisa Estudos de Paisagem nas Literaturas de Língua Portuguesa (UFMA/UFF/Capes), coordenado pela Profa. Dra. Márcia Manir Miguel Feitosa. E-mail: msjaneteserra@hotmail.com.

${ }^{2}$ Graduanda do curso de Letras-Francês da Universidade Federal do Maranhão. Pesquisadora do Grupo de Pesquisa Estudos de Paisagem nas Literaturas de Língua Portuguesa (UFMA/UFF/Capes) e Bolsista PIBIC-V com a pesquisa "A experiência do exílio na literatura contemporânea de língua portuguesa: a perspectiva do sujeito no espaço e na memória" (2012-2013), orientada pela Profa. Dra. Márcia Manir Miguel Feitosa. E-mail: vanessasc15@hotmail.com.
} 
canto das suas composições poéticas. Nesse sentido, pode-se afirmar que a poesia, desde sua gênese remota, está intimamente relacionada à música. Tal relação é perfeitamente entrelaçada à história da cultura literária portuguesa, pois as cantigas medievais de amor e de amigo, como o próprio nome sugere, eram composições musicais, que representam as obras inaugurais da poesia sentimental lusa.

Enquanto gênero literário tem como matéria-prima a palavra, concomitantemente, é arte e linguagem, que se apresenta como a verdadeira seara da imaginação e pela linguagem literária é produto do eu-lírico, que é autônomo para atribuir novos significados às palavras, bem como para criar novas realidades. Diante do mundo, o eu-poético manifesta o ser, o ver e o sentir através dos arranjos específicos da linguagem literária, que se expressa por meio da multissignificação, dos recursos estilísticos, do ritmo, da sonoridade e da musicalidade, bem como pela imagística, assim produz identidades pelas imagens e metáforas construídas pela sua potencialidade criadora.

No tocante à poesia brasileira de expressão modernista, observa-se que a sua poética integrou-se à criação literária de renomados letristas, como Vinícius de Moraes, uma das "pedras basilares" da Bossa Nova (novo estilo musical que transformou os rumos da música popular brasileira), na década de 1950. Compôs juntamente com Tom Jobim grandes clássicos musicais como Garota de Ipanema, Felicidade e Chega de saudade. Marcus Vinícius de Melo Moraes nasceu no Rio de Janeiro, em 19 de outubro de 1913. Foi diplomata, crítico cinematográfico, também cultivou a poesia, a crônica e o teatro. Sua profícua produção poética inicia-se na década de 1930 com uma imaginação criadora fortemente marcada pela angústia existencial e pelo anseio de superação, por meio da transcendência mística, os sentimentos de pecado, a culpa e o desconsolo proporcionados pela própria condição terrena intrínseca ao ser humano. Nos anos 40, volta-se para os aspectos cotidianos e simples da vida, explorando a temática do amor, do feminino e do erotismo. A linguagem literária, outrora vinculada aos modelos clássicos, torna-se mais livre e simples, adquirindo uma feição completamente modernista. No seu itinerário literário, ênfase para o Poema operário em construção, as obras Para viver um grande amor (1962), Para uma menina com uma flor (1966), a peça teatral Orfeu da Conceição (1956), que se transformou nos filmes Orfeu negro (1958), do diretor francês Marcel Camus; Orfeu (1998), do cineasta brasileiro Cacá Diegues.

Nessa perspectiva, no capítulo intitulado "poetas da geração pós-moderna", Carlos Nejar (2011, p. 477), aborda o poeta e a sua produção artística com a seguinte consideração: “e foi, aliás, inúmero o poeta Vinícius de Moraes, que conseguiu em vida - coisa rara - o 
afeto de sua gente. Onde era visto e ouvido, o apelido brotava, como se das entranhas do tempo: Poetinha". [Grifo original]. Ademais, importa para o presente estudo a contribuição desse poeta-letrista oferecida ao cânone da literatura infantil brasileira, com a obra $A$ arca de Noé (1974), que compõe o renomado acervo literário enquadrado no chamado boom do gênero no Brasil. Nessa perspectiva, pretende-se traçar algumas considerações acerca da poesia infantil desse período da estética literária destinada à infância, bem como enfatizar a linguagem e a construção poética de alguns poemas dessa antologia infantil, que se constitui em única obra do autor para crianças.

\section{A Poesis infantil brasileira}

A poesia destinada à infância se apresenta rica e com temáticas diversificadas, encontrando maior ressonância no espírito infantil porque está fundamentada na sensibilidade e na fantasia, com ampla exploração dos sentimentos e da sensorialidade, onde o ritmo e as rimas se coadunam à ludicidade da criança. A linguagem transpõe os sentidos óbvios e imediatos impregnada de simbologia e imagens, expressa o não-dito, indo além da racionalidade e do consciente.

Mas é válido ressaltar que esse novo paradigma dessa poética infantil contemporânea representa "o abandono da tradição didática que, por largo tempo, transformou o poema para crianças em veículo privilegiado de conselhos, ensinamentos e normas”. (ZILBERMAN; LAJOLO, 2009, p. 146). Nesse sentido, Mário Quintana, Cecília Meireles, Sidônio Muralha, Vinícius de Moraes, Ferreira Gullar, dentre outros representam a plêiade não compromissada com a clássica pedagogia dos valores tradicionais. Inspirados na poética do Modernismo, na qual já se inspirava os poemas para adultos desde a reviravolta dos valores estéticos provocada pela Semana de Arte Moderna, no começo da década de 1920. Desse modo, a poesia infantil "incorpora bem outra lição modernista: a de que o lirismo mais profundo pode ser trabalhado através dos temas mais prosaicos e mais cotidianos". (ZILBERMAN; LAJOLO, 2009, p. 152). Assim, inicia-se a ruptura com a atmosfera ideológica e parnasiana que movimentava a tradição poética de Olavo Bilac, marcada pelo conservadorismo formal e pelos ideais cívicos, patrióticos e familiares. Desse modo, até os anos 60 do século XX, a poesia infantil brasileira preservava reminiscências desse passado que apresentava temáticas a respeito dos animais, paisagens, valores nacionais, ufanistas e morais a partir do paradigma educativo. Uma vez que nesse período "a crença no poder comunicativo dos versos é tão forte 
que, ao longo da tradição da poesia infantil brasileira, valores ideológicos emergentes foram sempre confiados à força persuasória de poemas". (ZILBERMAN; LAJOLO, 2009, p. 147). Essa perspectiva do gênero literário infantil que, outrossim, inclui a produção em prosa, corroborou para que, durante muito tempo, a literatura infantil estivesse fora do âmbito acadêmico e da crítica literária. Porquanto era considerada um subgênero, uma vez que se atribuiu a ela uma função pragmática, com finalidade didática, visando ao controle do desenvolvimento intelectual e à manipulação das emoções da criança, apresentando-a apenas com o fim pedagógico de transmitir normas e contribuir para a formação moral infantil. Tal posicionamento acarretou um duplo preconceito. Ao ser considerada simplesmente como "histórias infantis", foi tratada como gênero de pouca relevância, desprovida de prestígio, de nobreza literária e de padrões estéticos, fator determinante para um processo inverso: por causa de tais julgamentos, acredita-se que pode ser destinadas para crianças.

A obra infantil em estudo, A arca de Noé, foi criada na década de 70 do século XX, período em que o gênero literário destinado às crianças se transforma em um objeto novo, produzido por meio da convergência de multilinguagens, da centelha de imaginação e magia, que fundem prazer e arte. É o chamado boom da literatura infantojuvenil que, de acordo com alguns críticos literários, ocorre no momento em que:

"A liberdade criadora que se havia atrofiado no período imediato após Lobato volta a fecundar a criação destinada à criança. Desvinculada de quaisquer compromissos pedagógicos [...] a nova literatura infantil/juvenil obedece às novas palavras de ordem: criatividade, consciência da linguagem e consciência crítica" (COELHO, 2000, p. 130).

Nesse sentido, durante a década de 1970, foi como se a literatura infantojuvenil brasileira reiniciasse a sua história literária. Nesse período, também eclodem narrativas infantojuvenis que rompem com a representação dos padrões de obediência e passividade, impostos ao comportamento infantil. No que tange à poesia infantil contemporânea, observase que o ponto de interseção entre o eu-poético e a infância "ocorre pela tematização do cotidiano infantil ou pela adoção, por parte do autor, de um ponto de vista que compartilha com seus pequenos leitores a anticonvencionalidade, quer da linguagem, quer do recorte da realidade". (ZILBERMAN; LAJOLO, 2009, p. 147). Assim, as obras literárias associam-se às crianças, tematizando sobre elas e dando-lhes voz, atendem aos anseios infantis, acentuando sua fase de desenvolvimento e de descoberta do mundo, de si e do outro, conseguindo também enfatizar seu potencial de criatividade, autonomia e rebelião. Outrossim, é oportuno 
ressaltar a contribuição dos escritores célebres da literatura não-infantil tanto para a prosa como para a poesia infantil, pois "todos os nossos grandes poetas, que não escreveram especialmente só para as crianças, dão-nos peças muito benfeitas e com profundo traço de simplicidade, o que permite trânsito livre para compreensão da infância e da adolescência." (ARROYO, 2011, p. 321).

Mediante o exposto não se pode acreditar que os critérios de análise da poética infantil sejam divergentes ou inferiores aos da poesia não-infantil, pois ela não é um objeto estético de menor valor literário e complexidade. Como muito bem observa Bordini (1986, p. 13), "aparentada, portanto ao ludismo, embora este não seja privativo da criança, a poesia infantil genuína é indistinguível da poesia não-adjetivada, salvo, talvez, em termos temáticos”. Nessa perspectiva, a poeticidade infantil também se constitui pelo equilíbrio dos diferentes níveis de articulação da enunciação, onde a palavra é o signo verbal por excelência da construção estética que se dá numa espécie de brincadeira com as palavras. Assim, as estrofes são dispostas de acordo com o jogo rítmico do poema e os versos possuem ressonâncias sonoras que se materializam pelas rimas, assonâncias, aliterações, paranomásias e por outras figuras de linguagem. Enfim, a utilização poética da linguagem verbal confere à poesia destinada às crianças ludicidade verbal e um imaginário-simbólico que subverte a realidade cotidiana. É justamente a valoração da ludicidade da linguagem que proporcionou a ampliação e fomento da poesia destinada às crianças, a partir da década de 1980, inserindo-a no paradigma do jogo, do divertimento e da brincadeira que abre as portas dos mundos mágicos e maravilhosos, criados pelo uso artístico que se faz da palavra.

\section{Análise poética dos poemas selecionados}

Para a análise literária da antologia selecionada para estudo, escolhemos os poemas: "A arca de Noé", "O girassol", "Os bichinhos e o homem" e "O pato". Acerca do título da obra literária nota-se o seu caráter motivador para o pequeno ou grande leitor, pois sugere o seu conteúdo poético. Dentro das simbologias da arca, a mais famosa é a da "Arca de Noé a navegar sobre as águas do dilúvio, contendo todos os elementos necessários à restauração cíclica. [...] é símbolo do cofre do tesouro, tesouro de conhecimento e de vida". (CHEVALIER; GHEERBRANT, 2012, pp. 73-74). Nesse sentido, o valor simbólico referenciado se coaduna à tematização da interação entre infância e natureza, relacionando-os de maneira livre e simples, onde a alegria da ingenuidade infantil encontra lugar nos 
elementos naturais, emergindo juntos na paisagem colorida, sinestésica e sensorial dessa poética. Como se pode observar no poema abaixo:

\section{A arca de Noé}

Sete em cores, de repente

$\mathrm{O}$ arco-íris se desata

Na água límpida e contente

Do ribeirinho da mata.

O sol, ao véu transparente

Da chuva de ouro e de prata

Resplandece resplendente

No céu, no chão, na cascata.

E abre-se a porta da arca

Lentamente surgem francas

A alegria e as barbas brancas

Do prudente patriarca.

Noé, o inventor da uva

E que, por justo e temente Jeová, clemente

Salvou da praga da chuva.

Tão verde se alteia a serra

Pelas planuras verdinhas

Que diz Noé: "Boa terra

Pra plantar as minhas vinhas!"

E sai levando a família

A ver; enquanto, em bonança

Colorida maravilha

Brilha o arco da aliança.

Ora vai, na porta aberta

De repente, vacilante

Surge lenta, longa e incerta

Uma tromba de elefante.

E logo após, no buraco

De uma janela, aparece

Uma cara de macaco

Que espia e desaparece.

Enquanto, entre as altas vigas

Das janelinhas do sótão

Duas girafas amigas

De fora as cabeças botam.
Grita uma arara, e se escuta

De dentro um miado e um zurro

Late um cachorro em disputa

Com um gato escouceia um burro.

A arca desconjuntada

Parece que vai ruir

Aos pulos da bicharada

Toda querendo sair.

Vai! Não vai! Quem vai primeiro?

As aves, por mais espertas

Saem voando ligeiro

Pelas janelas abertas.

Enquanto, em grande atropelo

Junto à porta de saída

Lutem os bichos de pelo

Pela terra prometida.

"Os bosques são todos meus!"

Ruge soberbo o leão

"Também sou filho de Deus!"

Um protesta; e o tigre - "Não!"

Afinal, e não sem muito custo Indo em fila, aos casais

Uns com raiva, outros com susto

Vão saindo os animais.

Os maiores vêm à frente

Trazendo a cabeça erguida

$\mathrm{E}$ os fracos, humildemente

Vêm atrás, como na vida.

Conduzidos por Noé

Ei-los em terra benquista

Que passam, passam até

Onde a vista não avista...

Na serra o arco-íris se esvai...

E... desde que houve essa história

Quando o véu da noite cai 
$\mathrm{Na}$ terra e os astros em glória

Enchem o céu de seus caprichos
É doce ouvir na calada

A fala mansa dos bichos $\mathrm{Na}$ terra repovoada.

(MORAES, 2004, p. 7)

O poema retoma o mito cristão da Arca de Noé, história segundo a qual Deus provocou um dilúvio que destruiu o mundo, salvando em uma arca apenas Noé, sua família e um casal de cada espécie de animal para repovoar a Terra. O poema dialoga com o texto bíblico e brinca com a imaginação infantil ao tentar descrever como poderia ter sido o desembarque dos passageiros dessa arca. A forma como o eu-lírico descreve o comportamento dos animais durante esse desembarque muito se assemelha ao comportamento infantil. Segundo Bordini (1986)

"[...] o leitor percebe que esse eu falante expressa desejos parecidos com os dele, leitor, e não com os esperáveis do adulto escritor. Assim, a impessoalidade desse eu, reconhecível só pelos seus desejos, leva a criança a identificar-se com ele" (p. 34).

No texto, isso se torna perceptível não através dos desejos expressos pelas personagens, mas sim através do seu comportamento. A curiosidade do macaco e da girafa, o barulho causado pela arara, pelo cachorro, pelo gato e pelo burro e a disputa para saber quem sairia primeiro da arca são características que compõem a personalidade de muitas crianças, permitindo assim que elas se identifiquem com o poema.

Segundo Bordini (1986), a natureza é uma das temáticas que compõem o universo da poesia infantil, sendo normalmente dada preferência aos animais domésticos. Em A arca de Noé, Vinícius de Moraes quebra com esse padrão ao fazer mais uso de animais selvagens do que de animais domésticos. Como dissemos anteriormente, a arca "é símbolo do cofre do tesouro, tesouro de conhecimento e de vida. É princípio de conservação e renascimento dos seres.”. (CHEVALIER; GHEERBRANT, 2012, p. 74). Assim, o poema convida - de forma implícita - a criança a refletir sobre a importância de cuidar e preservar os animais.

É possível perceber também que, no poema, o eu-lírico organizou as palavras de forma a criar rimas pobres ou ricas e predominantemente perfeitas. Além disso, essas rimas são, em quase todo o poema, cruzadas/alternadas. Isso contribui para aumentar a musicalidade presente no poema. Fato que se torna perceptível ao fazermos a leitura em voz alta de $A$ arca de Noé, momento no qual percebemos que o poema possui uma ritmicidade e uma melodia próprias que parecem se revelar à medida que a leitura é feita. 
Além disso, a maneira como o eu-lírico descreve as cenas narradas, no decorrer do poema, é extremamente visual. Ao fazer uso da imagética, o eu-lírico desperta e incentiva a imaginação da criança, facilitando o seu envolvimento com a história. Conforme Bordini (1986):

\begin{abstract}
"Não só de efeitos auditivos se faz o poema. O processo de apreensão do outro se inicia pelos órgãos sensoriais mais dependentes do contato (gosto, tato) e se estende aos distanciadores (olfato, audição e visão). Estes últimos, em especial a visão, comandam a apropriação intelectual da realidade e seu apuramento possibilita a autodeterminação no espaço físico e, depois, no social" (p. 26).
\end{abstract}

Posto isso, é perceptível que a ludicidade presente em A arca de Noé compõe-se, principalmente, de musicalidade e de imagética.

\title{
O girassol
}

Sempre o sol

Pinta de anil

Todo o céu

Fica um gentil

Carrossel.

O girassol é o carrossel das abelhas.

Pretas e vermelhas

Ali ficam elas

Brincando, fedelhas

Nas pétalas amarelas.

- Vamos brincar de carrossel, pessoal?

- "Roda, roda, carrossel

Roda, roda, rodador
Vai rodando, dando mel

Vai rodando, dando flor."

- Maribondo não pode ir que é bicho mau!

- Besouro é muito pesado!

- Borboleta tem que fingir de borboleta na entrada!

- Dona Cigarra fica tocando seu realejo!

- "Roda, roda, carrossel

Gira, gira, girassol

Redondinho como o céu

Marelinho como o sol."

E o girassol vai girando dia afora...

O girassol é o carrossel das abelhas.

(MORAES, 2004, p. 19).

Pode se afirmar que o significado do nome que o intitula é repleto de valor simbólico, pois "essa planta simboliza o Sol que gira e a luz móvel de que o Sol é a fonte". (CHEVALIER; GHEERBRANT, 2012, p. 485). É perceptível como o eu-lírico distribui as palavras nos versos, organizando-as pelo teor semântico que o conteúdo do poema requer, do mesmo modo que a escolha de cada palavra corrobora para o efeito rítmico e poético que se busca produzir. A lógica e o tecido de sentidos se dão, por exemplo, pelas metáforas empregadas nos versos 7, 22 e 23, bem como pela repetição de palavras que provoca 
reiteração de ideias como ocorrem nas $5^{\mathrm{a}}$ e $7^{\mathrm{a}}$ estrofes. A maioria das rimas são comuns/pobres como na $3^{\text {a }}$ estrofe, mas também são homofônicas como nos versos 1 e 3 da $7^{\text {a }}$ estrofe e, ainda, apresentam-se de forma "simpática e lúdica, com efeito mágico e belo" (ABRAMOVICH, 2006, p. 75). A utilização do ponto de interrogação e dos parênteses interrompe o esquema de linearidade do enunciado e aponta a intercalação de ideias, de sentimentos e de sensações que indica a liberdade do fluxo de consciência.

O convite feito ao leitor na $4^{\mathrm{a}}$ estrofe orienta a criança a se perceber como sujeito integrante do discurso poético, bem como a entender o posicionamento do eu-lírico que nele se manifesta como ser-criança. As últimas estrofes condensam os sentidos dados pela construção poética elaborada pelas palavras e pelas estruturas linguísticas que fazem a tessitura poética valer por si mesma e proporcionar o conflito entre o que nela ocorre e o que pode acontecer no ato da leitura literária, compreendida como um processo "circular e infinito" (LAJOLO, 2002, p.07). As imagens circulares nos versos "Roda, roda carrossel/ Roda, roda, rodador/ Gira, gira, girassol/ Redondinho como o céu" assumem o caráter cíclico da natureza tanto no seu habitat, como no tempo. No campo da representação simbólica, “o movimento circular é perfeito, imutável, sem começo nem fim, e nem variações; o que o habilita a simbolizar o tempo. [...] simboliza também o céu, de movimento circular e inalterável”. (CHEVALIER; GHEERBRANT, 2012, p. 250).[Grifos originais]. "E o girassol vai girando dia afora .... / O girassol é o carrossel das abelhas", além disso a circularidade representada pelos signos na esfera verbal simboliza a imagem da perfeição da natureza. Os mecanismos estilísticos comprovam também a característica solar da flor de formato radiado que cumpre sua função de contribuir para o equilíbrio ambiental juntamente com outros seres vivos integrantes das diversas cadeias responsáveis pela manutenção e preservação dos ecossistemas. Assim, a poesis infantil lida "com toda uma ludicidade verbal, sonora, às vezes musical, às vezes engraçada, no jeito como vão juntando palavras, fazendo com que se movam pela página quase como uma cantiga". (ABRAMOVICH, 2006, p. 67). É evidente que o advérbio "às vezes" não atinge a completude da sonoridade e musicalidade da poética infantil de Vinícius de Moraes, o que provoca fusão ou "confusão com a música". (ZILBERMAN, 2005).

De acordo com o Dicionário crítico da literatura infantil e juvenil brasileira, "Vinícius mostra em sua poesia, para crianças, a sua face lúdica/ingênua e o gesto descompromissado, espontâneo e brincalhão". (COELHO, 2006, p. 837). Tal consideração confirma-se, por exemplo, no poema $O$ pato, que também, segundo a autora, enfatiza o 
predomínio do bom humor e a exploração da ludicidade sonora na tessitura poética, mecanismo que conduz o leitor mirim ou ouvinte a sentir muito mais o ritmo e a musicalidade do que a carga semântica dos signos verbais.

\section{O pato}

Lá vem o pato

Pata aqui, pata acolá

Lá vem o pato

Para ver o que é que há.

O pato pateta

Pintou o caneco

Surrou a galinha

Bateu no marreco

Pulou do puleiro

No pé do cavalo

\author{
Levou um coice \\ Criou um galo \\ Comeu um pedaço \\ De jenipapo \\ Ficou engasgado \\ Com dor no papo \\ Caiu no poço \\ Quebrou a tigela \\ Tantas fez o moço \\ Que foi pra panela.
}

(MORAES, 2004, p. 34).

O fenômeno da dêixis empregado com a utilização dos advérbios de lugar nos versos 1 e 2 da $1^{\mathrm{a}}$ estrofe envolve os pequenos leitores e ouvintes, fazendo-os se identificar com o universo imaginário do discurso poético. As travessuras praticadas pelo bicho encontram conformidade com as vivências e peripécias infantis, conduzindo a imaginação para novos espaços, onde a potencialidade criadora do eu-lírico produz situações irreais como nos versos 6, 7, 8 e 9 da $2^{\text {a }}$ estrofe, mas aceitáveis na fantasia. Assim,

\footnotetext{
“[..] Vinícius, em seus poemas, representam animais que fogem à conduta do cão fiel ou do pássaro cativo. Em seus textos, os bichos protagonizam situações que se afastam do convencional e, com isso, mergulham a poesia infantil contemporânea num clima insólito e de estranhamento, caros à modernidade" (ZILBERMAN; LAJOLO, 2009, p. 151).
}

A repetição do fonema bilabial oclusivo /p/ confirma o tom humorístico do tecido poético que provoca a comicidade e o riso, bem como a exploração da sonoridade dos substantivos que nomeiam os bichos dão ao poema um caráter lúdico peculiar. Além disso, o fato do pato ser punido pelas suas "peraltices", evidenciada nos versos "Tantas fez o moço/Que foi pra panela", comprova que a poesia infantil modernista apresenta mudança na perspectiva de visualização do mundo pelo adulto, pois, "as normas da sociedade adulta são contestadas por sujeitos líricos bastante sintonizados com o modo de ser infantil, capazes de 
irreverência e malandragem, tanto quanto de ternura espontânea e desejo de justiça". (BORDINI, 1986, p.67).

\section{Os bichinhos e o homem}

\footnotetext{
Nossa irmã, a mosca

É feia e tosca

Enquanto que o mosquito

É mais bonito

É mais bonito.

Nosso irmão, besouro

Que é feito de couro

Mal sabe voar

Mal sabe voar.

Nossa irmã, a barata

Bichinha mais chata

É prima da borboleta

Que é uma careta

Que é uma careta.

Nosso irmão, o grilo

Que vive dando estrilo
}

Só pra chatear

Só pra chatear.

E o bicho-do-pé

Que gostoso que ele é

Quando dá coceira

Coça que não é brincadeira.

E o nosso irmão carrapato

Que é um outro bicho chato

É primo-irmão do bacilo

Que é irmão tranquilo

Que é irmão tranquilo.

E o homem que pensa tudo saber

Não sabe o jantar que os bichinhos vão ter

Quando o seu dia chegar

Quando o seu dia chegar

(MORAES, 2004, p. 26).

Em Os bichinhos e o homem, a temática dos animais se repete e novamente o eu-lírico rompe com o costume dos poemas infantis ao escolher animais não-domésticos. Porém, dessa vez, os animais que aparecem no poema são os insetos. Estes são elevados à mesma categoria dos seres humanos quando são considerados "nossa irmã" e "nosso irmão". Fato esse que poderia causar estranhamento aos adultos, mas que se torna aceitável dentro do universo infantil já que as crianças, muitas vezes, não fazem distinção entre os diferentes animais e ainda não aderiram à ideia de que os insetos são seres inferiores e considerados nojentos.

Além disso, o eu-lírico aborda implicitamente e de forma inusitada o tema da morte. Ele brinca com as palavras e constrói um poema aparentemente lúdico e ingênuo, mas que se revela irônico ao sugerir, na última estrofe, que um dia poderemos ser o jantar dos insetos. Dessa maneira, o poeta revela à criança a natureza frágil e vulnerável do ser humano e a convida a refletir sobre a morte. 
Esse poema possui uma tendência ao grotesco justamente por, em um primeiro momento, igualar os seres humanos aos insetos e, em um segundo momento, colocá-los em uma posição superior a nós ao sugerir que um dia seremos o jantar dos insetos.

Quanto à estrutura, Os bichinhos e o homem possui uma característica interessante que é a repetição do último verso de cada estrofe, produzindo uma espécie de eco. Esse fato, somado às rimas - predominantemente pobres, porém perfeitas - que compõem o poema, lhe conferem melodia, que é característica típica dos poemas de Vinícius de Moraes.

\section{Considerações finais}

A literatura infantil brasileira nasceu no século XIX e, por muito tempo, foi considerada uma forma de literatura inferior. Ela se consagra já no século XX, com a obra infantil de Monteiro Lobato. Dentre os diversos escritores brasileiros que, em algum momento de sua carreira, escreveram para o público infantil, temos o poeta Vinícius de Moraes.

Em A arca de Noé, sua única obra infantil, o poeta aborda principalmente temas relacionados à natureza. Além disso, ele busca aproximar seus poemas do universo infantil, atribuindo a seus personagens comportamentos e atitudes que são típicos das crianças. Dessa forma, Vinícius apresenta em seus poemas um eu-lírico com o qual as crianças possam se identificar e não um eu-lírico adulto se dirigindo a elas.

É perceptível também, nos poemas analisados, que o poeta faz um uso constante de rimas e brinca com as palavras explorando sua sonoridade e fazendo com que ritmo e melodia fluam naturalmente. Dessa forma, em alguns de seus poemas, "predominam o humor e a exploração lúdica das sonoridades do discurso poético, recurso que leva o pequeno leitor ou ouvinte a sentir os sons independentemente do que eles significam." (COELHO, 2006, p. 837). Além de fazer uso da musicalidade, Vinícius de Moraes se utiliza da imagética na construção de seus textos, criando assim poemas altamente visuais que estimulam a imaginação infantil.

É importante destacar também que os poemas analisados, muitas vezes, além de estimularem a imaginação infantil, convidam a criança para reflexão sobre diversos assuntos, a partir das interrelações fonológicas e semânticas que constituem a imagem poética, em que "subsiste, assim, como processo fundante de toda linguagem poética, a trama de imagem, pensamento e som”. (BOSI, 2000, p. 88). 


\section{Referências}

ABRAMOVICH, Fanny. Literatura infantil: gostosuras e bobices. São Paulo: Scipione, 2006. ARROYO, Leonardo. Literatura infantil brasileira. São Paulo: Editora Unesp, 2011.

BACHELARD, Gaston. A poética do devaneio. Trad. Antônio de Pádua Danesi. São Paulo: Martins Fontes, 2009.

BORDINI, Maria da Glória. Poesia infantil. São Paulo: Ática, 1986.

BOSI, Alfredo. O ser e o tempo da poesia. São Paulo: Companhia das Letras, 2000.

CHEVALIER, Jean. GHEERBRANT, Alain. Dicionário de símbolos: mitos, sonhos, costumes, formas, figuras, cores, números. Trad. Vera da Costa e Silva [et al.]. Rio de Janeiro: José Olympio, 2012.

COELHO, Nelly Novaes. Literatura Infantil: teoria, análise, didática. São Paulo: Moderna, 2000.

Dicionário crítico da literatura infantil e juvenil brasileira. São Paulo: Editora Companhia Nacional, 2006.

LAJOLO, Marisa. Do mundo da leitura para a leitura do mundo. São Paulo: Ática, 2002.

Ática, 2009.

ZILBERMAN, Regina. Literatura infantil brasileira: história e histórias. São Paulo:

MORAES, Vinícius de. A arca de Noé. São Paulo: Companhia das letrinhas, 2004.

NEJAR, Carlos. História da literatura brasileira: da carta de Caminha aos contemporâneos. São Paulo: Leya, 2011.

ZILBERMAN, Regina. Como e por que ler a literatura infantil brasileira. Rio de Janeiro: Objetiva, 2005.

<<www.bibliaonline.com.br>> Acesso em: 20/06/2013. 